\title{
One-handed revolving technique for soft cataract extraction
}

This article was published in the following Dove Press journal:

Clinical Ophthalmology

\author{
Bu Ki Kim \\ Su Joung Mun \\ Hyun Tae Choi \\ Young Hoon Yang \\ Ji Sun Kim \\ Jun Hyung Moon \\ Young Taek Chung \\ Onnuri Smile Eye Clinic, Seoul, Korea
}

Correspondence: Young Taek Chung

Onnuri Smile Eye Clinic, Hyobong

Building 9F I, Gangnam-daero 65 gil,

Seocho-gu, Seoul, Korea

Tel +82269130000

Fax +82 25325406

Email ytchungc@hanmail.net

\begin{abstract}
This study describes a new one-handed revolving technique for soft cataract extraction. Following hydrodissection, the endonucleus is removed piecemeal while the lens is rotated using a phaco tip. A peripheral groove is created in the 6 o'clock direction and, after lens rotation through $180^{\circ}$ using the phaco tip, another 6 o'clock groove is created. After a further $90^{\circ}$ of lens rotation, the residual plate is readily flipped over and emulsified. The entire procedure requires only a phaco tip; it is not necessary to create a corneal side port or use any instrument.
\end{abstract}

Keywords: cataract, phacoemulsification, one-handed technique, revolving technique, soft cataract

\section{Introduction}

Phacoemulsification is generally accepted as the standard technique for cataract surgery. As management of hard cataracts is difficult, even via phacoemulsification, most cataract techniques focus on how well the surgeon divides the hard nucleus. ${ }^{1-3}$ Many techniques use a chopper to divide or rotate the lens through a corneal side port; however, the chopper can tear the anterior or posterior capsule, causing zonulysis or lens drop. ${ }^{4}$ Creation of a corneal side port rotates the axis of astigmatism. ${ }^{5}$ Therefore, if use of a chopper is not mandatory, a one-handed technique affords many advantages.

We describe a technique facilitating soft lens removal using only a phaco tip, without a corneal side port.

\section{Surgical technique}

The one-handed revolving technique is most applicable for cataracts graded lens opacities classification system III (LOCS III) nuclear opalescence and nuclear color 3 or less, but it is also useful for firmer lenses. This technique can be performed under topical anesthesia. Surgery commences with a 2.8-mm long clear corneal incision. The anterior capsule is opened via continuous curvilinear capsulorhexis (CCC) at a diameter of $\sim 5.5 \mathrm{~mm}$ and hydrodissection is performed to completely separate the cortex from the capsule. The phaco tip is introduced into the anterior chamber in the bevel-down position, and the superficial cortex and the epinucleus of the center are removed. The next step is to remove the endonucleus. The phaco tip is embedded in the rim of the endonucleus and rotated slightly clockwise or counterclockwise. After 10-20 repeats, the endonucleus gets separated from the epinucleus and cortex (Figure 1A and B). After the endonucleus is removed by the phaco tip, a central hollow surrounded by a continuous rim of soft epinucleus is apparent. The phaco tip is moved forward to the 6 o'clock position and placed under the anterior capsule. By creating vacuum, the nuclear rim is drawn centrally and emulsified, creating a groove that runs to almost 

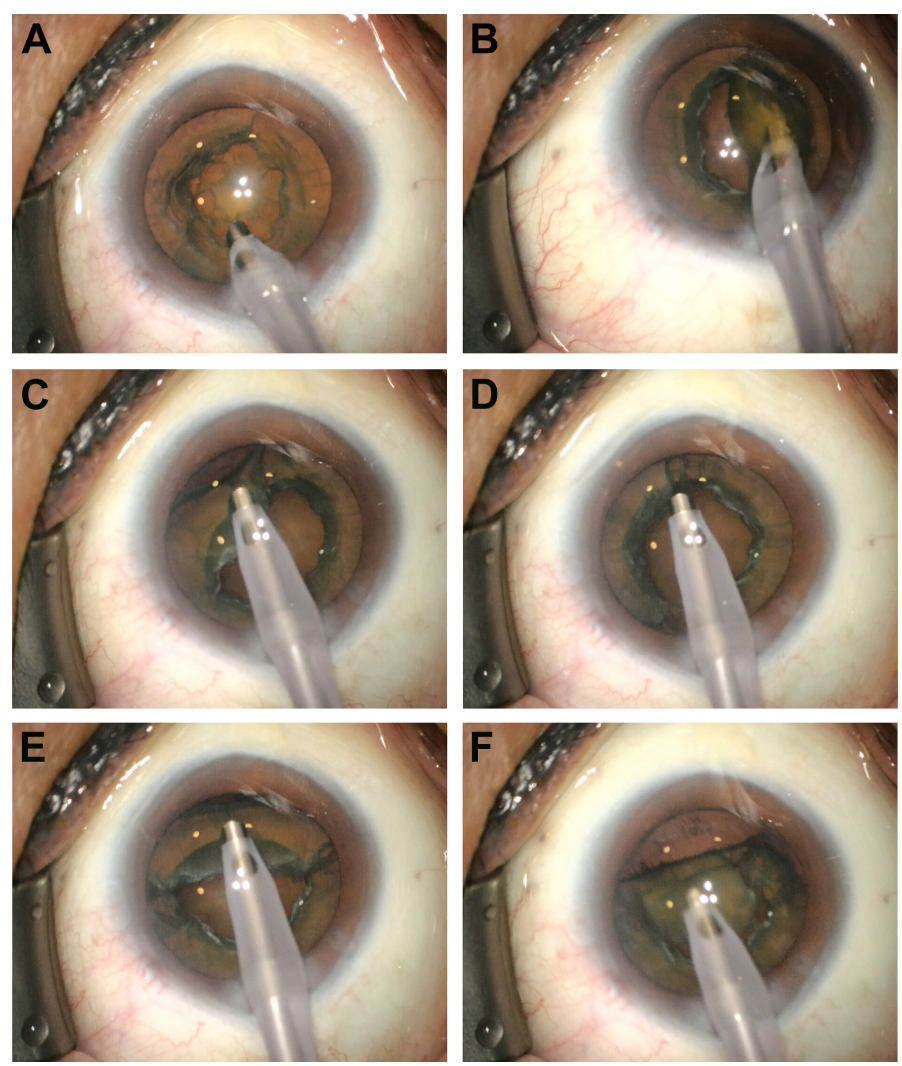

Figure I (A) After removal of the cortex and epinucleus, the rim of the endonucleus is removed piecewise while the lens is rotated by a phaco tip. (B) The endonucleus is dislocated by the phaco tip. (C) A peripheral groove is created from the lens equator to the $60^{\prime}$ 'clock position. (D) After lens rotation through $180^{\circ}$ using the phaco tip, a new groove is created. (E) After $90^{\circ}$ lens rotation using the phaco tip, the cortex and epinucleus are emulsified in the 6 o'clock direction. Next, the lens is folded along the grooves and separated from the posterior capsule. (F) The lens remnant is flipped and emulsified.

the equator of the lens (Figure $1 \mathrm{C}$ ). After $180^{\circ}$ rotation of the lens using the phaco tip, another groove is created in the same manner (Figure 1D). The ideal width of the groove is $\sim 2-3$ fold that of the phaco tip. Then, the lens is rotated by $90^{\circ}$ by using the phaco tip and, when the tip commences emulsification, the lens folds along the grooves and the upper half spills out of the posterior capsule (Figure 1E). After this step is repeated two-to-three times, the remnant of the lens flips over and can be easily emulsified (Figure 1F). After nuclear phacoemulsification is completed, an irrigation and aspiration tip is used to remove the residual cortical material, followed by implantation of the intraocular lens. Video S1 illustrates the technique. After the superficial cortex and the epinucleus of the center are removed, the rim of the endonucleus is removed piecewise by the phaco tip. A peripheral groove of the epinucleus is created in the 6 o'clock position, and after $180^{\circ}$ rotation of the lens, another groove is created. The lens is rotated $90^{\circ}$, and the epinucleus is emulsified in the 6 o'clock direction, then the lens folds along the grooves and the upper half spills out of the posterior capsule. After this step is repeated in the 5 and 7 o'clock directions, the remnant of the lens flips over and can be easily emulsified.

\section{Discussion}

Although phacoemulsification of hard cataracts has received much attention, softer cataracts often present challenges requiring special techniques. ${ }^{6,7}$ Malavazzi and Nery developed a visco-fracture technique for the removal of soft cataracts; the nucleus was divided using an ophthalmic viscosurgical device requiring low phaco energy and minimal manipulation, ${ }^{6}$ but the technique was appropriate only for soft cataracts and required a corneal side port. The chip-and-flip method of Fine was also useful to remove softer cataracts. ${ }^{7}$ After creation of a central bowl with an epinucleus and cortex via central sculpting, the subincisional nuclear rim was engaged using a second instrument and moved centrally, followed by carousel emulsification of the rim. ${ }^{7}$ The principle is similar to ours, but requires a corneal side port for the second instrument; our one-handed revolving technique needs only a phaco tip, and only the initial incision is required. Our technique is also easier; the residual plate tumbles in vacuum and the grooves split the plate horizontally. Kawahara et $\mathrm{al}^{5}$ compared the results of one- and twohanded phaco techniques; surgically induced astigmatism (SIA) torque was significantly higher in the two-handed 
rather than the one-handed technique, because a corneal side port was employed. Liyanage et $\mathrm{al}^{8}$ reported anterior chamber instability caused by the corneal side port during operation while employing a chopper. Also, the chopper may cause capsular rupture or zonular stress, especially in the hands of a novice.

Our technique is especially effective when toric intraocular lenses are placed; although the side port is smaller than the main incision in length, rotational effect of a corneal side port can affect the results. This aids surgeons who do not know that two-handed micromanipulation can trigger anterior chamber instability. Using our technique, the surgeon does not need to engage in deep sculpture near the posterior capsule; this avoids posterior capsular rupture. Moreover, this technique has the advantage of protecting the corneal endothelium, because most of the procedure is performed in the capsular bag and the phaco tip is bevel-down during emulsification.

We developed the technique to treat soft cataracts; experienced surgeons may also use it to treat moderateto-hard cataracts. Unlike other techniques, ours does not require prolapse of the nucleus into the anterior chamber during most of emulsification, so a hard nucleus can easily be removed with capsular and zonular support. We have used this technique in more than 1,500 cases without any significant complication, such as lens drop. However, this technique requires proper $\mathrm{CCC}$ and complete hydrodissection. If CCC is $<5.0 \mathrm{~mm}$ or the lens is not mobile because of poor hydrodissection, this technique should not be used, even though the lens is soft.

\section{Conclusion}

Our one-handed revolving technique is effective and safe when used to remove soft cataracts. No corneal side port (that can affect SIA) is required; no second instrument that might trigger anterior chamber instability or cause a capsular tear is needed. The technique is simple and can be used by both trainees and experienced surgeons. Further clinical studies are needed to compare objectively this technique with others in terms of SIA, change in corneal endothelial cell density, and the incidence of other complications.

\section{Disclosure}

The authors report no conflicts of interest in this work.

\section{References}

1. Aslan BS, Müftüoglu O, Gayretli D. Crater-and-split technique for phacoemulsification: modification of the crater-and-chop technique. J Cataract Refract Surg. 2012;38(9):1526-1530.

2. Kim DY, Jang JH. Drill and chop: modified vertical chop technique for hard cataract. Ophthalmic Surg Lasers Imaging. 2012;43(2):169-172.

3. Vasavada AR, Raj SM. Multilevel chop technique. J Cataract Refract Surg. 2011;37(12):2092-2094.

4. Kamoi K, Mochizuki M. Phaco forward-chop technique for managing posterior nuclear plate of hard cataract. J Cataract Refract Surg. 2010; 36(1):9-12.

5. Kawahara A, Kurosaka D, Yoshida A. Comparison of surgically induced astigmatism between one-handed and two-handed cataract surgery techniques. Clin Ophthalmol. 2013;7:1967-1972.

6. Malavazzi GR, Nery RG. Visco-fracture technique for soft lens cataract removal. J Cataract Refract Surg. 2011;37(1):11-12.

7. Fine IH. The chip and flip phacoemulsification technique. $J$ Cataract Refract Surg. 1991;17(3):366-371.

8. Liyanage SE, Angunawela RI, Wong SC, Little BC. Anterior chamber instability caused by incisional leakage in coaxial phacoemulsification. J Cataract Refract Surg. 2009;35(6):1003-1005.
Clinical Ophthalmology

\section{Publish your work in this journal}

Clinical Ophthalmology is an international, peer-reviewed journal covering all subspecialties within ophthalmology. Key topics include: Optometry; Visual science; Pharmacology and drug therapy in eye diseases; Basic Sciences; Primary and Secondary eye care; Patient Safety and Quality of Care Improvements. This journal is indexed on

\section{Dovepress}

PubMed Central and CAS, and is the official journal of The Society of Clinical Ophthalmology (SCO). The manuscript management system is completely online and includes a very quick and fair peer-review system, which is all easy to use. Visit http://www.dovepress.com/ testimonials.php to read real quotes from published authors. 